\title{
ARTIGO
}

\section{DIRETRIZES POLÍTICAS E ESTRATÉGICAS PARA A FORMAÇÃO DOCENTE VOLTADAS À PESQUISA E À EXTENSÃO: BRASIL}

\author{
Marta Lígia Pomim VALENTIM! \\ José Augusto Chaves GUIMARĀES 2
}

\section{RESUMO}

Caracterização das atividades de pesquisa dos docentes dos cursos de graduação em Ciência da Informação do país, enfocando-se os seguintes aspectos: pesquisa realizada para a obtenção de grau acadêmico; para cumprir requisitos institucionais e para a produção cientifica.

Palavras-chave: Ciência da Informação; Docentes; Pesquisa.

\begin{abstract}
Description of the research activities of Brazilian Library schools staff distinguishing the research done for degree awarding, from the institutional requirements, and from scientific production and publishing.
\end{abstract}

Key words: Information Science Schools; Staff; Research.

A definição de diretrizes políticas e estratégicas visando à formação docente da área de Biblioteconomia e Ciência da Informação constitui elemento fundamental para a maturidade docente, na medida em que permite a este último a inserção em um contexto de novos paradigmas de formação, em busca da excelência no ensino e da elaboração de corpora teóricos para a área.

Esse delineamento político-estratégico tem sido objeto de preocupação do Brasil, como se pode observar no texto da Lei de Diretrizes e Bases para a Educação Nacional - LDB (Lei n 9.394/96) que, entre seus diversos objetivos, busca oferecer

\begin{abstract}
"maior flexibilidade na organização curricular dos cursos, atendendo à necessidade de uma profunda revisão de toda a tradição que burocratiza os cursos e se revela incongruente com as tendências contemporâneas de considerar a formação em nível de graduação como uma etapa inicial da formação continuada; bem como à crescente heterogeneidade tanto da formação prévia como das expectativas e dos interesses dos alunos" (Imprensa, 2001).
\end{abstract}

Para viabilizar esse objetivo foram formadas Comissões de Especialistas, para cada área do

1. Presidente da Associação Brasileira de Ensino de Biblioteconomia, Documentação e Ciência da Informação (ABEBD), gestão 2001-2004, doutora em Ciência da Informação e Documentação pela Universidade de São Paulo (USP), professora da Universidade Estadual de Londrina (UEL). e-mail: valentim@uel.br

2. $1^{\circ}$ Secretário da Associação Brasileira de Ensino de Biblioteconomia, Documentação e Ciência da Informação (ABEBD), gestão 2001-2004, doutor em Ciências da Comunicação pela Universidade de São Paulo (USP), professor da Universidade Estadual Paulista (UNESP/Marília). e-mail: jaguima@terra.com.br 
conhecimento, no sentido de se estabelecerem diretrizes curriculares para os cursos de graduação. Entre os vários tópicos desenvolvidos, um está diretamente ligado ao corpo docente dos cursos.

No caso das Diretrizes Curriculares para a área de Biblioteconomia, foram delineadas algumas considerações, que afetam diretamente a formação docente, dentre elas:

\section{"Corpo Docente}

Em virtude de seu caráter profissional, os cursos exigem, na composição do corpo docente, uma preponderância de pessoal com titulação especifica, tanto quanto possivel em nivel de pós-graduação (Mestrado e Doutorado), respeitando as proporções indicadas na Lei de Diretrizes e Bases" (...)

\section{“Avaliações Periódicas}

As avaliações têm como foco a melhoria contínua das atividades docentes e discentes, contemplando, a par do desempenho acadêmico, a produção científica, os serviços de extensão à comunidade e a melhoria contínua dos processos de apoio administrativo..." (MEC, 2001).

A nova LDB estabelece que os cursos de graduação devem ter "um terço do corpo docente, pelo menos, com titulação acadêmica de mestrado ou doutorado (...) um terço do corpo docente em regime de tempo integral"' (SAVIANI, 1998, p.178). Assim, a legislação brasileira obriga as instituições de ensino superior, a definirem políticas de capacitação de docente, bem como a criarem mecanismos que facilitem essa formação, ou não poderão atuar no mercado educacional.

Além disso, o docente deve produzir ciência em sua área do conhecimento e, para isso, as instituições de ensino superior devem propiciar condições acadêmicas, administrativas e de fomento:

"As universidades são instituições pluridisciplinares de formação dos quadros profissionais de nível superior, de pesquisa, de extensão e de domínio e cultivo do saber humano, que se caracterizam por:

I. produção intelectual institucionalizada mediante estudo sistemático dos temas e problemas mais relevantes, tanto do ponto de vista cientifico e cultural, quanto regional e nacional" (SAVIANI, 1998, p.178).

Por outro lado, as avaliações periódicas dos cursos de graduação, por comissões especialmente constituídas para esse fim, exercerão importante papel, verificando as condições de ensino, pesquisa, extensão, objetivando a formação dos futuros profissionais da área.

Visando a atender à agenda Mercosul no que se refere aos Encontros de Diretores de Escolas de Biblioteconomia e Ciência da Informação para o delineamento de políticas conjuntas, procurou-se obter um panorama da formação docente, da pesquisa e da extensão, além de levantar dados sobre a produção científica, publicações e bolsas científicas na área, por meio de pesquisa realizada nas escolas de Biblioteconomia do país, pelos Coordenadores Regionais da Associação Brasileira de Ensino de Biblioteconomia, Documentação e Ciência da Informação (ABEBD) ${ }^{3}$ :

Para tanto, instituiu-se como instrumento de coleta de dados um questionário, aplicado pelos referidos Coordenadores Regionais, nas escolas que compõem a região geográfica de sua competência. Após a aplicação e devolução dos instrumentos, os Coordenadores Regionais realizaram as sistematizações dos dados por região, as quais foram

3. Coordenadores regionais da ABEBD: Região Norte: Prof. Dr. César Augusto de Castro (UFMA); Região Nordeste: Prof. Marilene L. Abreu Barbosa (UFBA); Região Centro-Oeste: Profa. Vera L. F. G. de Abreu (UFMG); Região Sudeste: Profa. Mara E. Fonseca Rodrigues (UFF); Região São Paulo: Profa. Dra. Elisabeth M. Martucci (UFSCar) e Região Sul: Prof. Dr. Oswaldo F. de Almeida Júnior (UEL) 
conjuntamente debatidas no VI Encontro Nacional de Ensino em Biblioteconomia e Ciência da Informação (ENEBCI), realizado de 30 de maio a 02 de junho de 2001, em Campinas.

É importante salientar que as 32 escolas de Biblioteconomia do país, distribuídas por 19 dos 26 Estados da Federação, possuem diferentes estruturas, englobando instituições de ensino público federal, instituições de ensino público estadual, instituições de ensino privadas, instituições de ensino confessionais e instituições de ensino comunitárias (Tabelas 1 e 2). Essa variável interfere sobremaneira numa análise de dados mais consistente.

Tabela 1. Escolas Públicas

\begin{tabular}{|l|l|}
\hline \multicolumn{1}{|c|}{ Instituições Federais } & Instituições Estaduais \\
\hline Universidade Federal & Universidade Estadual \\
\hline 1. do Amazonas (UFAM) & 1. do Rio de Janeiro (UNIRIO) \\
\hline 2. do Pará (UFPA) & 2. de São Paulo (USP) \\
\hline 3. do Maranhão (UFMA) & 3. Paulista (UNESP) \\
\hline 4. do Ceará (UFC) & 4. de Londrina (UEL) \\
\hline 5. do Rio Grande do Norte (UFRN) & 5.de Santa Catarina(UDESC) \\
\hline 6. da Paraíba (UFPB) & \\
\hline 7. de Pernambuco (UFPE) & \\
\hline 8. de Alagoas (UFAL) & \\
\hline 9. da Bahia (UFBA) & \\
\hline 10. de Minas Gerais (UFMG) & \\
\hline 11. do Espírito Santo (UFES) & \\
\hline 12. Fluminense (UFF) & \\
\hline 13. de Brasilia (UnB) & \\
\hline 14. de Goiás (UFG) & \\
\hline 15. do Mato Grosso (UFMT) & \\
\hline 16. de São Carlos (UFSCar) & \\
\hline 17. do Paraná (UFPR) & \\
\hline 18. de Santa Catarina (UFSC) & \\
\hline 19. do Rio Grande do Sul(UFRGS) & \\
\hline 20. de Rio Grande (FURG) & \\
\hline Total: 20 escolas & \\
\hline Total Geral: 25 escolas públicas & \\
\hline & \\
\hline
\end{tabular}

Tabela 2. Outros Tipos de Escolas

\begin{tabular}{|c|c|}
\hline $\begin{array}{c}\text { Instituições } \\
\text { Confessionais/Comunitária* }\end{array}$ & Instituições Privadas \\
\hline $\begin{array}{l}\text { 1. Pontificia Universidade Cató- } \\
\text { lica de Campinas (PUC-Campinas) }\end{array}$ & $\begin{array}{l}\text { 1. Fundação Escola de So- } \\
\text { ciologia e Política de São } \\
\text { Paulo (FESP) }\end{array}$ \\
\hline $\begin{array}{l}\text { 2. Faculdades Integradas Teresa } \\
\text { D'Ávilla (FATEA/St. André) }\end{array}$ & $\begin{array}{l}\text { 2. Faculdades Tereza Martin } \\
\text { FATEMA) }\end{array}$ \\
\hline $\begin{array}{l}\text { 3. Faculdades Integradas Teresa } \\
\text { D'Ávilla (FATEA/Lorena }\end{array}$ & $\begin{array}{l}\text { 3. Universidade Vale do Rio ver- } \\
\text { de de Três Corações (UNICOR) }\end{array}$ \\
\hline \multicolumn{2}{|l|}{$\begin{array}{l}\text { 4. Fundação Comunitária Formi- } \\
\text { guense (FUOM)* }\end{array}$} \\
\hline Total: 4 escolas & Total: 3 escolas \\
\hline $\begin{array}{r}\text { Total Geral: } 7 \text { escolas de } \\
\text { outros tipos }\end{array}$ & \\
\hline
\end{tabular}

Vale ainda ressaltar que, no decorrer dos últimos anos, algumas escolas tradicionais no ensino de biblioteconomia no país, fecharam seus cursos por motivos diferenciados. Como exemplo, pode-se citar a Universidade Santa Úrsula (USU), da cidade do Rio de Janeiro e as Faculdades Integradas Tiradentes (FIT), da cidade de Aracajú. Por outro lado, existem projetos de cursos que brevemente estarão sendo implementados, como é o caso do pioneiro Curso de Licenciatura em Biblioteconomia ${ }^{4}$, da Universidade Regional do Noroeste do Estado do Rio Grande do Sul (INIJUI).

Conforme já mencionado anteriormente, para fins de coleta de dados utilizou-se a estrutura da ABEBD, através de suas Coordenações Regionais, que refletem não apenas os distintos contextos socioeconômico e cultural do país, como também propiciam uma divisão eqüitativa de escolas. Desse modo, tem-se como regiões:

a. Norte: Amazonas, Pará e Maranhão;

b. Nordeste: Ceará, Rio Grande do Norte, Paraíba, Pernambuco, Alagoas e Bahia;

c. Centro-Oeste: Minas Gerais, Goiás, Distrito Federal e Mato Grosso;

d. Sudeste: Rio de Janeiro e Espirito Santo;

4. A formação bibliotecária em nível universitário no Brasil dá-se apenas pela modalidade de bacharelado (voltado para a pesquisa e o exercício profissional), ao passo que as licenciaturas destinam-se à formação de professores para o curso fundamental e médio, ao passo que nos demais países do Mercosul, a expressão Licenciatura corresponde, na exata medida, naquilo que a legislação brasileira se denomina Bacharelado. 
e. São Paulo: São Paulo;

f. Sul: Paraná, Santa Catarina e Rio Grande do Sul.

Antes de apresentar a sistematização dos dados, faz-se necessário discorrer sobre o entendimento da $\mathrm{ABEBD}$ quanto à pesquisa docente: é atividade científica desenvolvida no âmbito das universidades, ponto fundamental para o crescimento e maturidade docente e discente. Nesse contexto, entende-se que a maturidade científica do pesquisador tem reflexos positivos diretos no desenvolvimento do processo de ensino e aprendizagem, resultando em benefícios para os alunos.

No caso brasileiro pode-se categorizar a pesquisa docente em três momentos diferentes: 1) a realização de pesquisa visando à obtenção de grau acadêmico (mestrado, doutorado, livre-docência); 2) a realização de pesquisa por exigência da própria estrutura universitária e, 3) a realização de pesquisa para a produção científica.

Demo afirma que pesquisa é

"o processo que deve aparecer em todo trajeto educativo, como princípio educativo que é, a base de qualquer proposta emancipatória. Se educar é sobretudo motivar a criatividade do próprio educando, para que surja o novo mestre, jamais discipulo, a atitude de pesquisa é parte intrínseca. Pesquisa toma ai contornos muito próprios e desafiadores, a começar pelo reconhecimento de que o melhor saber é aquele que sabe superar-se"(1992, pp.16-17).

Nesse sentido, entende-se pesquisa como um princípio educativo, base para o desenvolvimento e formação de um indivíduo em relação ao "saber pensar". O processo educacional deve fornecer ao discente a competência de "saber pensar". Essa competência deve ser desenvolvida e acompanhada por um professor que também tenha essa competência. Diante do exposto, Demo define o que é ser professor: "a. em primeiro lugar, é pesquisador, nos sentidos relevados: capacidade de diálogo com a realidade, orientado a descobrir e a criar, elaborador da ciência, firme em teoria, método, empiria e prática;

b. é, a seguir, socializador de conhecimentos, desde que tenha bagagem própria, despertando no aluno a mesma noção de pesquisa;

c. é, por fim, quem, a partir de proposta de emancipação que concebe e realiza em si mesmo, torna-se capaz de motivar o novo pesquisador no aluno, evitando de todos os modos reduzi-lo a discípulo subalterno" (1992, p.48).

A pesquisa tem importante papel na formação dos indivíduos e, por meio dela, o aluno tem contato com a realidade da área e conhece sua teoria. A partir daí é possível estabelecer relações que viabilizem a criação de novos paradigmas científicos para a área.

A metodologia utilizada para a coleta de dados junto às escolas obedeceu aos seguintes critérios:

\section{a. Titulação Docente}

- Somente docentes alocados no Departamento ou Curso de Biblioteconomia, não considerar docentes alocados em outros Departamentos que ministram aulas no Curso de Biblioteconomia;

- Apenas os docentes concursados/efetivos, não considerar docentes temporários, substitutos ou similares;

- Considerar a última titulação obtida.

\section{b. Publicação}

- O curso possui algum periódico/revista: a) próprio, produzido e gerenciado pelo Curso ou Departamento em que o curso está alocado; b) em conjunto com outro Curso ou Departamento da instituição e, c) não possui;

- O periódico/revista tem: a) Comissão Editorial; b) Editor responsável; c) não possui Comissão Editorial e, d) não possui Editor responsável;

- A periodicidade do periódico/revista; 
- O periódico/revista está indexado em alguma fonte nacional ou internacional.

\section{c. Atividades de Pesquisa Docente e Discente}

- Somente docentes alocados no Departamento ou Curso de Biblioteconomia, não considerar docentes alocados em outros Departamentos que ministram aulas no Curso de Biblioteconomia;

- Apenas os docentes concursados/efetivos, não considerar docentes temporários, substitutos ou similares;

- Apenas projetos desenvolvidos na área de Ciência da Informação;

- Considerar os recursos (bolsas, etc.) recebidos no ano de 2000;

- Considerar os recursos recebidos de agências: a) nacionais públicas; b) nacionais privadas; c) estaduais públicas; d) estaduais privadas; e) municipais públicas; f) municipais privadas; $g$ ) internacionais; $h$ ) própria IES e, i) outros tipos.

\section{d. Inserção dos Docentes e Discentes em Grupos de Pesquisa}

- Somente docentes alocados no Departamento ou Curso de Biblioteconomia, não considerar docentes alocados em outros Departamentos que ministram aulas no Curso de Biblioteconomia;

- Apenas os docentes concursados/efetivos, não considerar docentes temporários, substitutos ou similares;

- Considerar apenas os Grupos de Pesquisa cadastrados no CNPq.

\section{e. Produção Científica do Corpo Docente}

- Somente docentes alocados no Departamento ou Curso de Biblioteconomia, não considerar docentes alocados em outros Departamentos que ministram aulas no Curso de Biblioteconomia;

- Apenas os docentes concursados/efetivos, não considerar docentes temporários, substitutos ou similares;

- Considerar apenas a produção científica dos últimos 5 anos;

- Não considerar relatórios de estágio, monitoria ou atividades acadêmicas similares;

- Não considerar nenhum outro tipo de produção científica a não ser os relacionados.

É importante salientar que 31 das 32 escolas existentes responderam ao instrumento de coleta de dados. Ainda assim, vale ressaltar que algumas questões não foram respondidas por todas as escolas, dificultando, em alguns casos, uma sistematização mais precisa. Por isso, a ABEBD, se propôs a desenvolver a complementação dos dados faltantes, com o intuito de permitir análises mais aprofundadas.

Buscou-se, através do instrumento de coleta de dados, mapear os cursos de Biblioteconomia quanto à titulação do corpo docente e a quantidade de docentes em capacitação, conforme metodologia mencionada anteriormente (Tabela 3). A partir do levantamento obteve-se um total de 456 docentes que atuam diretamente ligados aos cursos de Biblioteconomia no país, o que indica uma média de 14.1 docentes por curso.

Em termos de estágio de formação/capacitação, observa-se o seguinte panorama (Tabela 3):

Tabela 3. Titulação e Capacitação Docente no Brasil*

\begin{tabular}{|l|c|c|c|c|c|c|c|}
\hline \multicolumn{1}{|c|}{ Categoria } & Norte & Nordeste & Centro-Oeste & Sudeste & São Paulo & Sul & Total \\
\hline Pós-Doutorado & 0 & 0 & 3 & 0 & 7 & 2 & 12 \\
\hline Doutorado Concluido & 3 & 12 & 24 & 3 & 24 & 18 & 84 \\
\hline Doutorado em Andamento & 1 & 13 & 10 & 11 & 13 & 10 & 58 \\
\hline Mestrado Concluido & 25 & 39 & 11 & 17 & 23 & 25 & 140 \\
\hline Mestrado em Andamento & 4 & 4 & 2 & 1 & 16 & 10 & 37 \\
\hline Especialização Concluida & 12 & 18 & 23 & 8 & 28 & 4 & 93 \\
\hline Especialização em Andamento & 3 & 0 & 0 & 1 & 0 & 0 & 4 \\
\hline Apenas Graduação & 15 & 2 & 1 & 0 & 7 & 3 & 28 \\
\hline Total & $\mathbf{6 3}$ & $\mathbf{8 8}$ & 74 & 41 & 118 & 72 & 456 \\
\hline
\end{tabular}

* Dados de 2001 
Da análise geral dos dados, observa-se que 294 docentes $(65,69 \%)$ possuem titulação mínima de mestre e $96(21,05 \%)$ possuem titulação mínima de doutor. Tais dados revelam aspectos positivos se comparados com a realidade verificada pela ABEBD em 1992, quando apenas $30 \%$ dos docentes brasileiros possuíam titulação mínima de mestre. Por outro lado, considerando-se que a legislação brasileira considera oficialmente como investigadores apenas aqueles possuidores do título de doutor ${ }^{5}$, pode-se dizer que a massa crítica da área é composta por cerca de $21 \%$ dos docentes. É importante registrar, ainda que $2,63 \%$ dos docentes possuem pós-doutorado.

Uma análise regional dos dados revela que a titulação docente é tanto maior naquelas regiões onde existem programas de pós-graduação stricto sensu (mestrado e doutorado).

Em termos de política de capacitação docente e considerando a última titulação obtida verifica-se uma alta demanda dos docentes quanto à realização do doutorado (Figura 1). Do total de 456 docentes no país, $43 \%$ possuem apenas o título de mestre, o que indica uma necessidade do estabelecimento de políticas que viabilizem a capacitação docente em nível de doutorado de forma mais agressiva, de modo a incrementar a massa crítica nos cursos de Biblioteconomia.

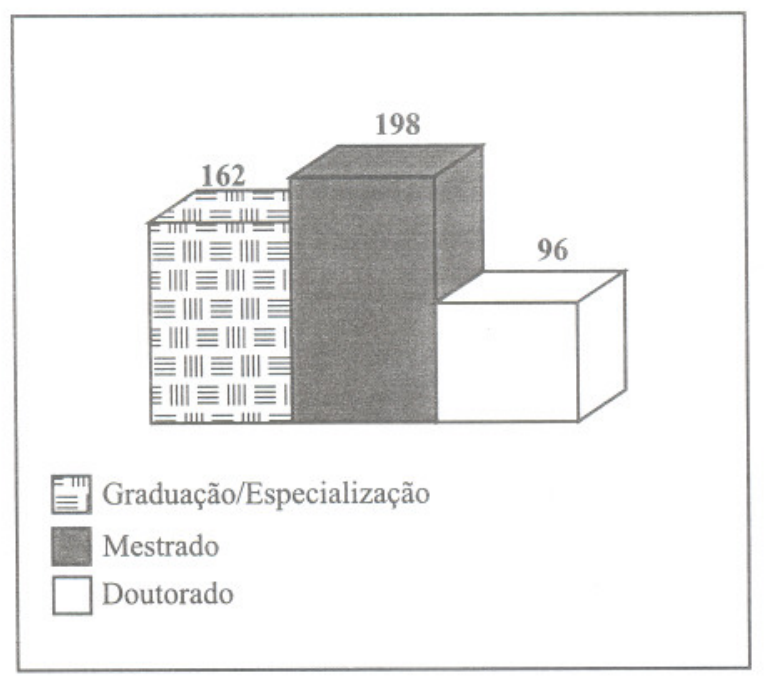

Figura 1. Titulação Docente no Brasil em 2001
Vale ressaltar que nesse panorama atual, muitos docentes estão buscando a capacitação em nível de mestrado e de doutorado: dos 456 docentes vinculados aos cursos de Biblioteconomia do país, $59 \%$ do total de docentes com titulação de mestre estão fazendo doutorado e $37 \%$ do total de docentes com titulação de bacharel ou especialista estão fazendo mestrado. Dessa maneira, foi possível elaborar um prognóstico para o ano de 2004 (Figura 2) da titulação docente no país, na área de Biblioteconomia.

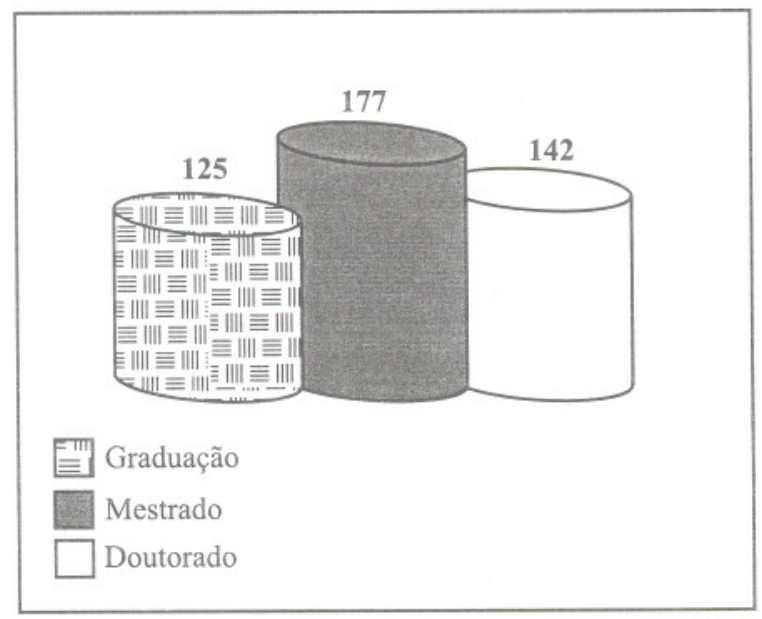

Figura 2. Prognóstico da Titulação Docente para 2004

Analisando-se comparativamente as Figuras 1 e 2 observa-se uma situação ao menos animadora em termos de perspectivas de capacitação docente, visto que o número de docentes sem pós-graduação stricto sensu (mestrado ou doutorado) tende a se reduzir, nos próximos anos, na ordem de $22,83 \%$, assim como se estima uma redução de $10,60 \%$ para docentes com apenas mestrado, aspecto que se compensa por uma estimativa de crescimento de $47,91 \%$ do número de docentes doutores.

Em termos de diretrizes políticas e estratégicas visando uma capacitação mais efetiva do corpo docente da área de Ciência da Informação, é importante que haja a criação de novos programas de pós-graduação em nível de mestrado e doutorado, nas diferentes regiões do país. Atualmente existem

5. É importante ressaltar que a legislação brasileira prevê que o docente seja portador de título de mestre para poder cursar o doutorado. 
11 programas de pós-graduação no país (Anexo 1). No entanto, ainda não atendem à demanda existente, principalmente pelo fato de estarem concentrados em algumas regiões geográficas do país, aspecto que exige grandes e custosos deslocamentos dos docentes.

Além disso, cumpre gestionar junto à Coordenação de Aperfeiçoamento de Pessoal de Nível Superior (Capes), agência governamental federal que coordena os trabalhos e estabelece políticas e diretrizes para o país, o investimento em diferentes modalidades de bolsas, visando a atender diferentes demandas institucionais, procurando contemplar não apenas bolsas de dedicação exclusiva (40 horas) ao programa de pós-graduação a que o docente vai se vincular (fato que muitas vezes inviabiliza a liberação do docente por parte da instituição, pois esta não possui mecanismos de substituição do docente no período em que está em capacitação), mas as bolsas parciais (como a modalidade auxílio-deslocamento), em que o docente pode, concomitantemente, cursar a pós-graduação e permanecer integrado às atividades de ensino, pesquisa e extensão do respectivo curso.

Outra hipótese a ser encarada é aquela em que o docente obtém a liberação parcial $(12,16$ ou 20 horas) por parte da instituição, mas não possui recursos que viabilizem suas despesas de viagem, alimentação ou mesmo mensalidade do programa de pós-graduação, dificultando da mesma forma sua necessidade/vontade de capacitar-se. Por esses motivos, faz-se necessária uma revisão nas regras da Capes quanto ao fomento da capacitação docente no país.

Outro item mapeado pelo instrumento de coleta de dados, foi se os cursos de Biblioteconomia do país possuíam algum periódico/revista conforme metodologia anteriormente mencionada. Das 31 escolas pesquisadas, apenas 6 delas $(19 \%)$ informaram possuir periódicos produzidos e gerenciados pelo próprio curso ou departamento (Anexo 2), sendo que todos são indexados em fontes internacionais.
Das 16 escolas que afirmaram possuir algum tipo de periódico (Figura 3), a maioria com periodicidade semestral, a categorização foi apresentada da seguinte forma: a) próprio; b) em conjunto; c) outro; d) não possui.

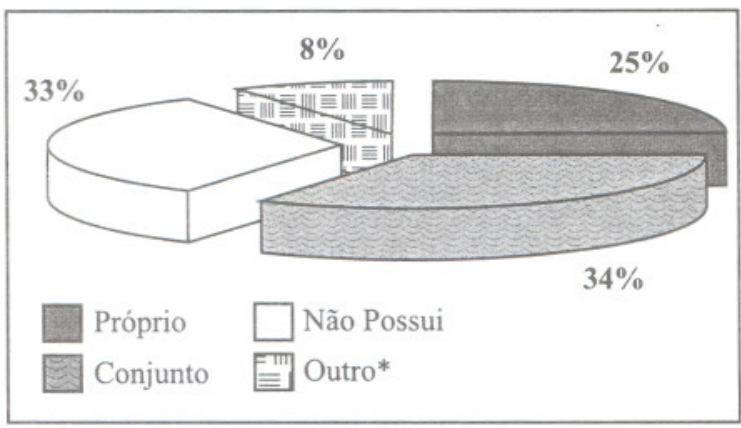

* Outro: refere-se a periódicos de cunho geral, editados pela instituição.

Figura 3. Periódicos/Revistas das Escolas

Essa realidade apresentada na Figura 3, demonstra que a maioria das instituições não possuem recursos financeiros e humanos que viabilizem a produção de periódicos. Na maioria das vezes a produção da publicação é esforço de um ou de alguns docentes. Outro fato que pode estar relacionado ao pequeno número de periódicos na área é o baixo percentual da comunicação científica na área, ou seja, docentes, profissionais etc., nem sempre divulgam suas pesquisas; além disso, os dados levantados denotam a urgente necessidade de maior fomento à pesquisa científica na área de Ciência da Informação.

O Conselho Nacional de Desenvolvimento Científico e Tecnológico (CNPq), agência governamental federal que viabiliza grande parte do fomento à pesquisa no país, recebe recursos do orçamento federal. No entanto, os recursos destinados ao $\mathrm{CNPq}$, são muito pequenos quando comparados aos recursos que países do primeiro mundo destinam à pesquisa. Uma das linhas de fomento que o $\mathrm{CNPq}$ disponibiliza está voltada à edição de publicações científicas. Para isso, a instituição deve enviar um projeto com o exemplar do periódico editorado, solicitando recursos para o pagamento dos custos de impressão do referido 
número. É necessário ressaltar que o projeto enviado ao CNPq solicitando recursos para a publicação de um periódico requer que o mesmo esteja pronto, o que muitas vezes inviabiliza sua realização.

Nesse sentido, é importante que a ABEBD tenha várias linhas editoriais, abrindo espaço para a comunicação científica de temáticas voltadas à: a) formação do profissional da informação; b) ensino das diversas sub-áreas da Ciência da Informação; c) didática e pedagogia do ensino na área da Ciência da informação; d) perspectivas e atuação profissional, entre outras.

A partir dessa visão político-estratégica a ABEBD, nesta gestão de 2001-2004, estará implementando as seguintes ações ${ }^{6}$ :

- Criação de uma revista eletrônica - de caráter científico, objetivando dar maior espaço para a' produção científica dos profissionais da área de Ciência da Informação;

- Criação da série "Estudos ABEBD" - de caráter técnico-científico, objetivando divulgar pesquisas desenvolvidas pelos docentes e discentes da área;
- Criação dos "Cadernos Didáticos ABEBD"de caráter didático, objetivando o fazer pedagógico do docente da área de Ciência da Informação;

- Prêmio ABEBD - visando premiar o melhor Trabalho de Conclusão de Curso (TCC) desenvolvido pelo alunado dos cursos de Biblioteconomia do país.

Outro item levantado pelo instrumento de pesquisa, conforme metodologia anteriormente mencionada (Figura 4), foi verificar o apoio à pesquisa docente e discente na área de Ciência da Informação, recebido através das agências de fomento. O levantamento possibilitou identificar que, atualmente no país, foram distribuídas 256 bolsas de iniciação científica aos discentes e 140 bolsas de algum tipo de produtividade em pesquisa aos docentes da área.

Considerando que a área possui aproximadamente 456 docentes na área, dos quais 96 são no mínimo doutores, e considerando a quantidade de bolsas distribuídas pelas agências de fomento nacionais ${ }^{7}$, isto é, 42 bolsas, pode-se considerar que provavelmente $43 \%$ dos docentes com título de doutor têm apoio para desenvolverem pesquisa, o

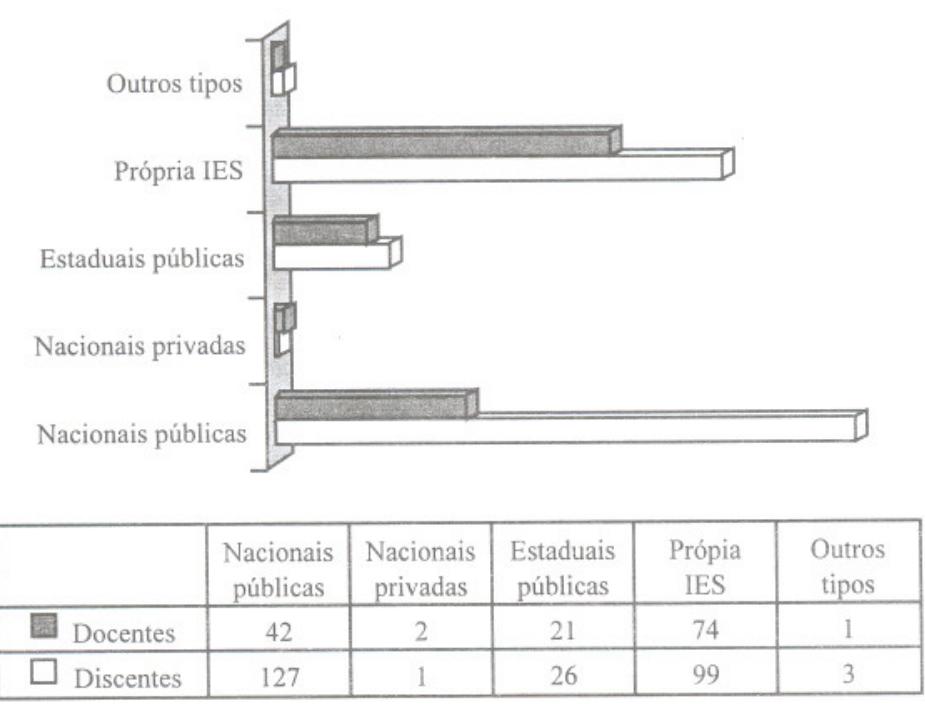

Figura 4. Apoio à Pesquisa - Bolsas

6. Conforme discutido e aprovado no VI ENCONTRO NACIONAL DE ENSINO DE BIBLIOTECONOMIA E CIÊNCIA DA INFORMAÇÃO (Campinas-SP, 30 maio - 2 jun. 2001).

7. Um dos critérios utilizados pelas agências governamentais federais é que o docente deve ter obrigatoriamente o título de doutor para solicitar bolsas científicas. 
que representa um número bastante significativo. No entanto, esta consideração merece uma verificação mais exata.

Levantou-se também, através do instrumento de coleta de dados, a quantidade de grupos de pesquisa existentes nas escolas de Biblioteconomia do país (Figura 5), conforme metodologia anteriormente mencionada. Foram identificados 38 grupos de pesquisa, cadastrados no Diretório de Grupos de Pesquisa do CNPq, distribuídos pelas 31 escolas respondentes. É importante ressaltar que muitos grupos de pesquisa existentes nas escolas de biblioteconomia, não foram considerados por não estarem cadastrados no Diretório do CNPq, uma vez que este era um dos critérios metodológicos que deveriam ser considerados na coleta de dados junto das escolas.

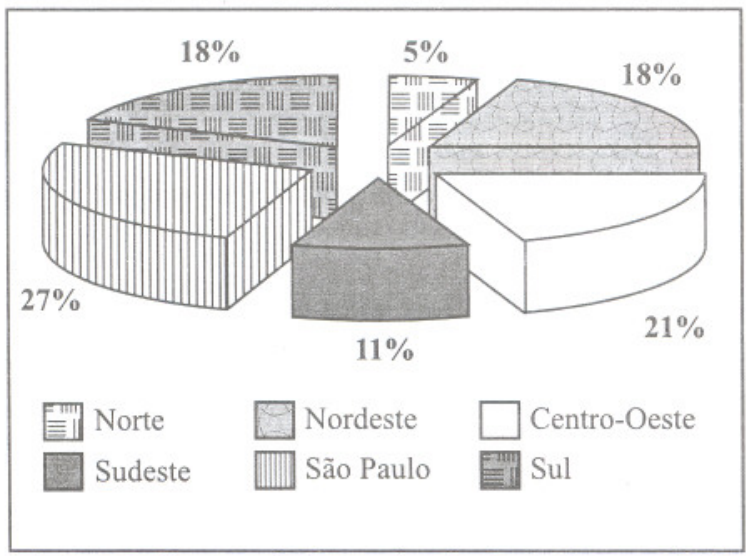

Figura 5. Grupos de Pesquisa Cadastrados no CNPq
Finalizando a coleta de dados, foi levantado junto às escolas a produção científica do corpo docente (Tabela 4), conforme metodologia anteriormente mencionada, visando um mapeamento geral da disseminação/comunicação científica dos docentes.

Uma análise mais aprofundada dos dados coletados, em relação à produção científica, não foi realizada, por vários motivos. Dentre eles, o fato de que muitas escolas não informaram de forma quantitativa a produção científica, inviabilizando assim maiores comentários ou inferências sobre o total coletado. Outro fator que motivou essa decisão está relacionado ao próprio instrumento de coleta de dados, que não contemplou diferenciações quanto aos periódicos que possuíam referees ou corpo editorial, característica que dimensiona a qualidade do periódico. Além disso, os dados anteriormente apresentados, não representam a maioria das escolas respondentes.

De qualquer forma, percebe-se pela amostra coletada das escolas respondentes, um total de 1.850 diferentes tipos de produção científica publicados nos últimos 5 anos, ao relacionar esse total aos 294 docentes com titulação de mestrado e doutorado, obtém-se uma média de 6.2 publicações por docente. Da produção científica mais significativa, ou seja, artigos em periódicos nacionais e internacionais e

Tabela 4. Produção Científica Docente

\begin{tabular}{|c|c|c|c|c|c|c|c|}
\hline Produção Científica & Norte & Nordeste & Centro-Oeste & Sudeste & São Paulo & Sul* & Total \\
\hline Artigos em Periódicos Nacionais & 31 & 34 & 88 & 27 & 221 & 25 & 426 \\
\hline Artigos em Periódicos Internacionais & 7 & 29 & 15 & 4 & 42 & 6 & 103 \\
\hline Livros & 8 & 12 & 19 & 13 & 30 & 1 & 83 \\
\hline Capítulos de Livro & 8 & 15 & 14 & 22 & 68 & 4 & 131 \\
\hline Artigos em Eventos da Área de Ciência da Inform. & 31 & 107 & 52 & 59 & 264 & 19 & 532 \\
\hline Artigos em Eventos de outras Áreas & 9 & 14 & 28 & 16 & 43 & 2 & 112 \\
\hline Resumos em Eventos da Área de Ciência da Inform. & 0 & 25 & 39 & 39 & 76 & 12 & 191 \\
\hline Resumos em Eventos de outras Áreas & 8 & 1 & 24 & 14 & 26 & 1 & 74 \\
\hline Artigos em Jornais & 9 & 26 & 15 & 0 & 127 & 21 & 198 \\
\hline Total & 111 & 263 & 294 & 194 & 897 & 91 & 1.850 \\
\hline
\end{tabular}

* Algumas escolas somente informaram a média e não quantificaram a produção cientifica, conforme o instrumento solicitava. 
livros e capítulos de livros, os artigos científicos publicados em periódicos nacionais, $57 \%$ do total, aparecem de forma expressiva em relação aos outros tipos de produção, o que reafirma a necessidade do país produzir um maior número de periódicos, visando a divulgação científica.

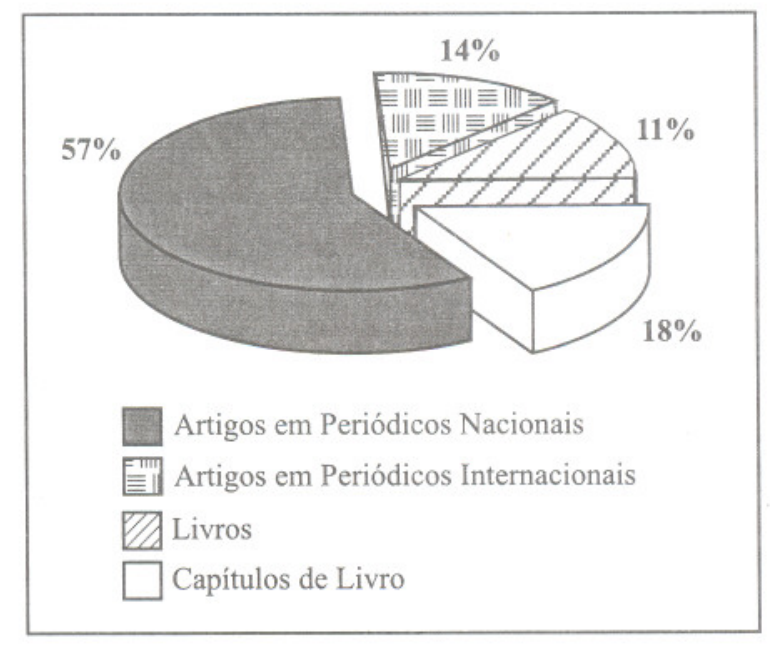

Figura 6. Produção Científica Docente - Mais Significativo

Também é importante mencionar que a relação dos itens constantes na produção científica, da tabela 4, foram extraídos dos critérios CNPq/Capes de avaliação quanto a produção científica nacional.

O Encontro Nacional de Ensino em Biblioteconomia e Ciência da Informação, realizado pela ABEBD trienalmente desde 1986, tem reforçado, a cada edição ${ }^{8}$, a imprescindibilidade da pesquisa docente, objetivando:

- Evitar um ensino de natureza meramente reprodutora de conhecimentos;

- Garantir o compromisso da universidade com a constante construção do conhecimento;

- Propiciar que o docente possa ser um paradigma de pesquisador para o aluno;

- Criar o compromisso do profissional docente com a consolidação científica da área.

A pesquisa, portanto, é a base, o alicerce do crescimento e amadurecimento de uma determinada área do conhecimento, daí decorrendo o compromisso que cada docente deve ter com a sua área científica, com clara compreensão de sua importância para o próprio amadurecimento enquanto docente.

Desnecessário é, pois, relembrar que o reconhecimento de uma área científica se faz com seus pesquisadores e suas pesquisas.

\section{REFERÊNCIAS BIBLIOGRÁFICAS}

DEMO, P. Pesquisa: princípio científico e educativo. 3.ed. São Paulo: Cortez: Autores Associados, 1992.120 p. (Biblioteca de Educação - Série I - Escola, 14)

DEMO, P. Saber pensar. São Paulo: Cortez: Instituo Paulo Freire, 2000. 159p. (Guia da Escola Cidadã, 6)

IMPRENSA Oficial. Gabinete do Ministro: despachos do ministro em 4 de julho de 2001. Disponível em: http://www.imprensanacional.br. Acesso em 10 jul. 2001.

MEC. Diretrizes curriculares para os cursos de graduação. Disponível em: http://www.mec.gov.br/Sesu/ diretriz.shtm. Acesso em 10 jul. 2001.

SAVIANI, D. A nova lei da educação: trajetória, limites e perspectivas. 4.ed. Campinas: Autores Associados, 1998. 242p. (Coleção Educação Contemporânea)

\section{ANEXO I}

\section{Programas de Pós-Graduação em Ciência da Informação}

1. Pontifícia Universidade Católica de Campinas (PUC-Campinas) - Mestrado.

2. Universidade de Brasília (UnB) - Mestrado e Doutorado em Ciência da Informação.

3. Universidade de São Paulo (USP) - Mestrado e Doutorado em Ciência da Informação e Documentação.

4. Universidade Federal de Minas Gerais (UFMG) Mestrado e Doutorado em Ciência da Informação.

5. Universidade Federal da Paraíba (UFPb) Mestrado em Ciência da Informação.

8. Recife (1986), Brasília (1989), São Paulo (1992), São Paulo (1995), São Carlos-SP (1998) e Campinas-SP (2001). 
6. Universidade Federal do Rio de Janeiro/Instituto Brasileiro de Informação em Ciência da Tecnologia (UFRJ/IBICT) - Mestrado e Doutorado em Ciência da Informação.

\section{Programas de Pós-Graduação em Ciência da Informação Cursos Novos}

7. Universidade Estadual Paulista (UNESP/Marília) Mestrado em Ciência da Informação

8. Universidade Federal da Bahia (UFBA) Mestrado em Ciência da Informação

9. Universidade Federal de Pernambuco (UFPE) Mestrado em Comunicação e Informação

10. Universidade Federal do Rio Grande do Sul (UFRGS) - Mestrado em Comunicação e Informação

11. Universidade Federal de Santa Catarina (UFSC) Mestrado em Ciência da Informação

\section{ANEXO 2}

Lista de Periódicos Informados pelas

Escolas na Coleta de Dados:

\section{Região Norte:}

1. InfoCiência - UFMA - São Luís/MA http://www.ufma.br/

\section{Região Nordeste:}

1. Informação\&Sociedade - UFPB - João Pessoa/PB http://www.informacaoesociedade.ufpb.br/

\section{Região Centro-Oeste:}

1.Perspectivas em Ciência da Informação-UFMG Belo Horizonte/MG http://www.eb.ufmg.br/pci/

2. Revista de Biblioteconomia de Brasília - UnB Brasília/DF http://www.unb.br/fa/cid/rbb/rev.htm

\section{Região São Paulo:}

1. Transinformação-PUC-Campinas-Campinas/SP http://www.puccamp.br/ biblio/transinformacao/welcome.html>

\section{Região Sul:}

1. Encontros Bibli - Revista de Biblioteconomia e Ciência da Informação da UFSC -UFSC Florianópolis/SC http://www.ced.ufsc.br/bibliote/encontro/ 